\title{
Clinical significance of epithelial mesenchymal transition (EMT) in chronic obstructive pulmonary disease (COPD): potential target for prevention of airway fibrosis and lung cancer
}

\author{
Sukhwinder Singh Sohal', Malik Quasir Mahmood and Eugene Haydn Walters
}

\begin{abstract}
Unfortunately, the research effort directed into chronic obstructive pulmonary disease (COPD) has been disproportionately weak compared to its social importance, and indeed it is the least researched of all common chronic conditions. Tobacco smoking is the major etiological factor. Only 25\% of smokers will develop "classic" COPD; in these vulnerable individuals the progression of airways disease to symptomatic COPD occurs over two or more decades. We know surprisingly little about the pathobiology of COPD airway disease, though small airway fibrosis and obliteration are likely to be the main contributors to physiological airway dysfunction and these features occur earlier than any subsequent development of emphysema. One potential mechanism contributing to small airway fibrosis/obliteration and change in extracellular matrix (ECM) is epithelial mesenchymal transition (EMT), so called Type-II EMT. When associated with angiogenesis (Type-III EMT) it may well also be a link with the development of lung (airway) cancer which is closely associated with COPD. Active EMT in COPD may help to explain why lung cancer is so common in smokers and also the core pathophysiology of small airway fibrosis. Better understanding may lead to new markers for incipient neoplasia, and better preventive management of patients. There is serious need to understand key components of airway EMT in smokers and COPD, and to demarcate novel drug targets for the prevention of lung cancer and airway fibrosis, as well as better secondary management of COPD. Since over $90 \%$ of human cancer arises in epithelia and the involvement of EMT in all of these may be a central paradigm, insights gained in COPD may have important generalizable value.
\end{abstract}

Keywords: COPD; Lung cancer; Small airways; Large airways; Airway remodelling; Fibrosis; Epithelium; Rbm fragmentation; Smoking; Fibroblasts/myofibroblasts

\section{Background}

Epithelial mesenchymal transition (EMT) is a process in which epithelial cells undergo a transition to a motile mesenchymal phenotype [1]. It can be considered as a marker of profound epithelial plasticity [2]. Elizabeth Hay from Harvard University was the first to describe the process of "epithelial mesenchymal transformation" in 1982, and then in 1995 as an important process involved in embryogenesis and organ development [3-5]. In the intervening time, the term "transformation" had

\footnotetext{
*Correspondence: sssohal@utas.edu.au

NHMRC Centre of Research Excellence for Chronic Respiratory Disease and Lung Ageing, School of Medicine, University of Tasmania, MS-1, 17 Liverpool Street Private Bag-23, Hobart, TAS 7000, Australia
}

been replaced with the term "transition", indicating potential induction and reversibility of the process, even potentially a two-way process from mesenchymal cells to epithelium [6]. This reverse process has been termed "mesenchymal-epithelial transition" (MET), but there are very few examples of this in the literature and most are concerned with embryogenic kidney formation [1].

The classically described process of EMT involves phenotypic change and migration of epithelial cells into the sub-epithelial mesenchyme in the lamina propria (LP) to function as extracellular-matrix producing fibroblasts/ myofibroblasts [7-11]. EMT is a vital process during embryogenesis (Type I EMT), but can also be induced as a result of persistent damage and tissue inflammation 
$[1,12,13]$. There are then two subsequent outcome possibilities with active EMT: severe and even complete organ fibrosis (Type II EMT), development of a premalignant stroma when associated with angiogenesis (Type III EMT) [1,7-16].

This complex process of EMT involves essential changes in a wide range of proteins gained, maintained or attenuated [13], but most of the studies reported in the literature have been able to focus on only a few specific markers and are likely to be far from complete. More importantly which proteins/pathways are amendable to current therapeutics and which will require new modalities of interaction are not clearly understood. In this editorial we will focus on recent advances made in evidence of active processes of EMT in airway disease and its potential clinical importance especially in COPD, and with the use of analysis of what we know from other organ disease processes.

\section{Main text}

We recently published that EMT is an active process in large airways of COPD patients $[17,18]$. Thus in smokers but especially in current smoking COPD, epithelium is in an activated state, staining strongly positive for epidermal growth factor receptor (EGFR). At the same time, the underlying reticular basement membrane (Rbm) is highly fragmented with many clefts, which itself is a structural change strongly suggestive of active EMT. Further the clefts contain cells staining for "classic" EMT markers, namely the proteolytic enzyme matrix-metalloproteinase-9 (MMP-9), mesenchymal markers including fibroblast protein S100A4 and vimentin and epithelial markers including cytokeratin [17]. EMT-marker expressing cells are also abundantly present in the basal epithelium (BE), and Rbm cells stain positively for both epithelial and mesenchymal markers [18]. Furthermore, the Rbm in large airways is hyper-vascular [14-16] i.e. give the appearance of active EMT type-III, and of course it is the large airways in COPD, where cancer formation is common, especially squamous cell carcinoma [1,6,7].

The other prime pathology associated with COPD is small airway fibrosis and obliteration, and this could potentially be related to active Type-II EMT at this site, if such would be demonstrated [8-11]. It is suggested that key players in fibrosis are fibroblasts/myofibroblasts populations. The origin of these cells is still debated in literature, if they are locally produced or bone marrow derived, but, in some circumstances EMT has been strongly implicated as a major source of these cells and can significantly change ECM characteristics of the airway wall. These changes in the ECM can alter the stiffness characteristics of the airways, perhaps paradoxically making them more floppy and vulnerable to expiratory dynamic compression and obstruction during expiration [19]. We believe that active EMT-Type-II is potentially contributing to these fibroblasts/myofibroblasts populations in the small airways hence leading to ECM changes and eventually leading to fibrosis/obliteration of these airways [8-11]. Although there are substantial reports on extracellular matrix changes in other lung diseases such as interstitial lung disease (ILD), idiopathic pulmonary fibrosis (IPF), and asthma, investigations into changes in the ECM in COPD patients are limited [19]. This warrants further studies.

Milara et al. did indeed recently report that EMT is an active process also in small airways of COPD patients and potentially contributing to small airway fibrosis [20]. In a separate study authors reported marked regression of EMT by roflumilast $\mathrm{N}$-oxide, a PDE4 inhibitor in bronchial epithelial cells in vitro by restoring cellular cyclic adenosine monophosphate (cAMP) levels [21]. Wang and colleagues further elaborated this concept by demonstration of increased Urokinase-type plasminogen activator receptor (uPAR) expression, in the small airway epithelium of patients with COPD, participating in an active EMT process [22]. Authors also further demonstrated that targeted silencing of uPAR using small hairpin RNA (shRNA) inhibited cigarette smoke induced EMT in human small airway epithelial cells. However, little has yet been published as therapeutic potential to block EMT in COPD airways apart from Wang and Milara study which demonstrates so by restoring cAMP and inhibiting uPAR [21,22].

We recently reported [23] in a randomized controlled trial that inhaled corticosteroid fluticasone propionate given over six months suppressed EMT-related changes in large airways of COPD patients. This trial showed marked reduction in $\mathrm{Rbm}$ fragmentation (core structural hallmark of EMT), epidermal growth factor receptor (EGFR), basal epithelial cell S100A4 expression and in Rbm cell S100A4 and MMP-9 in the active inhaled corticosteroids (ICS) compared to placebo [23]. This is the first study reporting anti-EMT effects of inhaled corticosteroids in COPD, where of course they are widely used as putative "anti-inflammatory" agent, although that mode of operation is far from convincing [24]. In human epidemiological studies it is strongly suggested that patients on inhaled corticosteroids, albeit only at high doses (as used in our study), are associated with an appreciable (50\%) reduction in the risk of lung cancer [25-27]. We suggest EMT might be the process by which this effect of ICS occurs. If this is true, it has huge implications for therapeutic and public health policy, since it is strongly suggested in literature that patients on ICS are associated with a decreased risk for lung cancer. It is suggested that statins may also have similar effects on EMT in COPD, since lung cancer risk decreases in COPD patients who are on statins [28], this warrants further studies.

We are not alone in recognising such possibilities. Thus, recently in lung adenocarcinoma, vaccination against drivers 
of EMT was proposed as an immunotherapeutic approach against tumor progression, which is also attracting interest from pharmaceutical industries and in fact adenocarcinoma is now getting more common compared to squamous cell carcinoma. The investigators developed an immunotherapeutic approach to target a major driver of EMT, the T-box transcription factor $\mathrm{T}$ (also known as brachyury) [29]. This therapeutic phenomenon is currently being tested in patients with advanced carcinomas in the context of a Phase I clinical trial [30,31]. This approach is expected to generate an effective T-cell $(\mathrm{CD} 8+)$ response that selectively eradicates tumor cells expressing the EMT driver of choice and undergoing EMT switch. When employed in combination with conventional chemotherapy eliminate epithelial tumor cells $[29,30]$. It is of interest and relevance in this context that over $90 \%$ of human cancer arises in epithelia (eg breast, colon, stomach, liver, prostate, ovary/fallopian tube, bladder), and the involvement of EMT in all of these may be a central paradigm [32-34]. COPD-related cancer may well be just another example of this core principle of unstable epithelium in the context of tissue inflammation and/or chronic stimulation [19].

In another study epigenetic based inhibition of EMT by sorafenib has been reported in human lung epithelial cells (A549, a lung adenocarcinoma cell line). Sorafenib (Nexavar or BAY 43-9006) is a small molecular inhibitor that targets a number of serine/threonine and receptor tyrosine kinases, and is the first oral agent approved for the clinical treatment of a variety of tumor types since 2005 by the US Food and Drug Administration. In this study, the authors reported that sorafenib inhibited TGF- $\beta 1$-induced EMT by increasing histone acetyltranferase (HAT) expression and by decreasing histone deacetylase expression possibly via inhibition of Ras/Raf MAPK and ErbB signaling [35]. Camera et al. also suggested TGF- $\beta 1 / \mathrm{Smad} 2 / 3$ as a potential therapeutic target for EMT [36]. Yang et al. further demonstrated that crosstalk between muscarinic acetylcholine receptor (mAChR) and TGF- $\beta 1$ can lead to EMT induction in lung epithelial cells (A549) suggesting a role of non-neuronal cholinergic system in EMT and a potential novel therapeutic target for EMT [37].

Byers and colleagues reported that in non-small cell lung cancer (NSCLC) inhibition of Axl-RTK (another receptor tyrosine kinase) by SGI-7079 lead to decrease in growth of NSCLC tumors. The authors suggested Axl-RTK as a potential therapeutic target for overcoming EGFR inhibitor resistance associated with mesenchymal transition [38]. Similar effects of sorafenib are observed in liver [39] and urothelial carcinoma in situ [40] by targeting STAT3 and urokinase plasminogen activator (uPA). Recently in idiopathic pulmonary fibrosis, efficacy of Nintedanib (multiple tyrosine kinases inhibitor) and pirfenidone (an anti-fibrotic and anti-inflammatory drug) has been reported in improving lung function [41,42]. It is quite possible that these drugs might also affect the process of EMT or are inducing their therapeutic effect at least partly by blocking EMT, since EMT has been shown to be active in IPF [43]. Nintedanib works mainly by inhibiting angiogenesis so it may have implications for EMT-Type-III where angiogenesis is prominent and on the other hand Pirfenidone is more anti-fibrotic in action so may have implications for EMT-Type-II. These warrant further studies, as they may have both anti-fibrotic and anti-cancer effects through EMT.

\section{Conclusions}

EMT is an important process in airway disease especially in smoking related COPD, where it might be contributing to small airway fibrosis and large airway epithelial cancers. However there are very few studies reporting anti-EMT effects of different drugs and data are especially sparse from in vivo human clinical investigations. Most of the conclusions are drawn from in vitro studies. Therapeutic approaches to EMT are still in their infancy and we don't know which protein or pathways we should target to block this profound epithelial plasticity. Given the fact that disease-associated EMT is of two types, it becomes more complicated to tease out what proteins/pathways are contributing independently to fibrosis and cancer and what therapeutic modalities will they require since BOTH types share the EMT proteome, but empirically seem to differ only in the neo-angiogenesis component.

\section{Competing interests}

The authors declare that they have no competing interests.

\section{Authors' contributions}

SSS, MQM and EHW made intellectual contributions and drafted the manuscript. All authors read and approved the final manuscript.

\section{Acknowledgements}

This work was supported by Royal Hobart Hospital Research Foundation (RHHRF; S0022103).

Received: 19 August 2014 Accepted: 12 September 2014

Published online: 11 November 2014

\section{References}

1. Kalluri R, Weinberg RA: The basics of epithelial-mesenchymal transition. $J$ Clin Invest 2009, 119(6):1420-1428.

2. Willis BC, Borok Z: TGF-beta-induced EMT: mechanisms and implications for fibrotic lung disease. Am J Physiol Lung Cell Mol Physiol 2007, 293(3):L525-534

3. Hay ED: Interaction of embryonic surface and cytoskeleton with extracellular matrix. Am J Anat 1982, 165(1):1-12.

4. Hay ED: An overview of epithelio-mesenchymal transformation. Acta Anat (Basel) 1995, 154(1):8-20.

5. Guarino M, Tosoni A, Nebuloni M: Direct contribution of epithelium to organ fibrosis: epithelial-mesenchymal transition. Hum Pathol 2009, 40(10):1365-1376.

6. Kalluri R, Neilson EG: Epithelial-mesenchymal transition and its implications for fibrosis. J Clin Invest 2003, 112(12):1776-1784.

7. Sohal SS, Soltani A, Weston S, Wood-Baker R, Walters H: Intermediate filament vimentin and potential role in epithelial mesenchymal transition (EMT). In Vimentin concepts and molecular mechanisms; 2013:37-61. 
8. Sohal SS, Walters EH: Epithelial mesenchymal transition (EMT) in small airways of COPD patients. Thorax 2013, 68(8):783-784.

9. Sohal SS, Walters EH: Role of epithelial mesenchymal transition (EMT) in chronic obstructive pulmonary disease (COPD). Respir Res 2013, 14(1):120

10. Sohal SS, Ward C, Danial W, Wood-Baker R, Walters EH: Recent advances in understanding inflammation and remodeling in the airways in chronic obstructive pulmonary disease. Expert Rev Respir Med 2013, 7(3):275-288.

11. Sohal SS, Ward C, Walters EH: Importance of epithelial mesenchymal transition (EMT) in COPD and asthma. Thorax 2014.

12. Kalluri R: EMT: when epithelial cells decide to become mesenchymal-like cells. J Clin Invest 2009, 119(6):1417-1419.

13. Zeisberg $M$, Neilson $E G$ : Biomarkers for epithelial-mesenchymal transitions. J Clin Invest 2009, 119(6):1429-1437.

14. Soltani A, Muller HK, Sohal SS, Reid DW, Weston S, Wood-Baker R, Walters EH: Distinctive characteristics of bronchial reticular basement membrane and vessel remodelling in chronic obstructive pulmonary disease (COPD) and in asthma: they are not the same disease. Histopathology 2012, 60(6):964-970.

15. Soltani A, Reid DW, Sohal SS, Wood-Baker R, Weston S, Muller HK, Walters EH: Basement membrane and vascular remodelling in smokers and chronic obstructive pulmonary disease: a cross-sectional study. Respir Res 2010 11(1):105.

16. Soltani A, Sohal SS, Reid D, Weston S, Wood-Baker R, Walters EH Vessel-associated transforming growth factor-Beta1 (TGF-beta1) is increased in the bronchial reticular basement membrane in COPD and normal smokers. PLoS One 2012, 7(6):e39736.

17. Sohal SS, Reid D, Soltani A, Ward C, Weston S, Muller HK, Wood-Baker R, Walters EH: Reticular basement membrane fragmentation and potential epithelial mesenchymal transition is exaggerated in the airways of smokers with chronic obstructive pulmonary disease. Respirology 2010, 15(6):930-938

18. Sohal SS, Reid D, Soltani A, Ward C, Weston S, Muller HK, Wood-Baker R, Walters EH: Evaluation of epithelial mesenchymal transition in patients with chronic obstructive pulmonary disease. Respir Res 2011, 12(1):130.

19. Nowrin K, Sohal SS, Peterson G, Patel R, Walters EH: Epithelial-mesenchymal transition as a fundamental underlying pathogenic process in COPD airways: fibrosis, remodeling and cancer. Expert Rev Respir Med 2014, 1-13.

20. Milara J, Peiro T, Serrano A, Cortijo J: Epithelial to mesenchymal transition is increased in patients with COPD and induced by cigarette smoke. Thorax 2013.

21. Milara J, Peiro T, Serrano A, Guijarro R, Zaragoza C, Tenor H, Cortijo J: Roflumilast $\mathrm{N}$-oxide inhibits bronchial epithelial to mesenchymal transition induced by cigarette smoke in smokers with COPD. Pulm Pharmacol Ther 2014, 28(2):138-148.

22. Wang $Q$, Wang $Y$, Zhang $Y$, Xiao W: The role of uPAR in epithelial-mesenchymal transition in small airway epithelium of patients with chronic obstructive pulmonary disease. Respir Res 2013, 14:67.

23. Sohal SS, Soltani A, Reid D, Ward C, Wills KE, Muller HK, Walters EH: A randomized controlled trial of inhaled corticosteroids (ICS) on markers of epithelial-mesenchymal transition (EMT) in large airway samples in COPD: an exploratory proof of concept study. Int I Chron Obstruct Pulmon Dis 2014, 9:533-542.

24. Reid DW, Wen Y, Johns DP, Williams TJ, Ward C, Walters EH: Bronchodilator reversibility, airway eosinophilia and anti-inflammatory effects of inhaled fluticasone in COPD are not related. Respirology 2008, 13(6):799-809.

25. Parimon T, Chien JW, Bryson CL, McDonell MB, Udris EM, Au DH: Inhaled corticosteroids and risk of lung cancer among patients with chronic obstructive pulmonary disease. Am J Respir Crit Care Med 2007, 175(7):712-719.

26. Kiri VA: Inhaled corticosteroids and lung cancer chemoprevention in chronic obstructive pulmonary disease patients: what should we make of what we observe? Annals of respiratory medicine 2010, 1(2):23-30

27. Kiri VA, Fabbri LM, Davis KJ, Soriano JB: Inhaled corticosteroids and risk of lung cancer among COPD patients who quit smoking. Respir Med 2009, 103(1):85-90.

28. Young RP, Hopkins R, Eaton TE: Pharmacological actions of statins: potential utility in COPD. Eur Respir Rev 2009, 18(114):222-232.

29. Palena C, Fernando Rl, Hamilton DH: An immunotherapeutic intervention against tumor progression: targeting a driver of the epithelial-tomesenchymal transition. Oncoimmunology 2014, 3(1):e27220
30. Roselli M, Fernando RI, Guadagni F, Spila A, Alessandroni J, Palmirotta R, Costarelli L, Litzinger M, Hamilton D, Huang B, Tucker J, Tsang KY, Schlom J, Palena C: Brachyury, a driver of the epithelial-mesenchymal transition, is overexpressed in human lung tumors: an opportunity for novel interventions against lung cancer. Clin Cancer Res 2012, 18(14):3868-3879.

31. Hamilton DH, Litzinger MT, Fernando Rl, Huang B, Palena C: Cancer vaccines targeting the epithelial-mesenchymal transition: tissue distribution of brachyury and other drivers of the mesenchymal-like phenotype of carcinomas. Semin Oncol 2012, 39(3):358-366.

32. Garber K: Epithelial-to-mesenchymal transition is important to metastasis, but questions remain. J Natl Cancer Inst 2008, 100(4):232-233. 239.

33. Barnes PJ, Adcock IM: Chronic obstructive pulmonary disease and lung cancer: a lethal association. Am J Respir Crit Care Med 2011, 184(8):866-867.

34. de Torres JP, Marin JM, Casanova C, Cote C, Carrizo S, Cordoba-Lanus E, Baz-Davila R, Zulueta JJ, Aguirre-Jaime A, Saetta M, Cosio MG, Celli BR: Lung cancer in patients with chronic obstructive pulmonary diseaseincidence and predicting factors. Am J Respir Crit Care Med 2011, 184(8):913-919.

35. Zhang J, Chen YL, Ji G, Fang W, Gao Z, Liu Y, Wang J, Ding X, Gao F: Sorafenib inhibits epithelial-mesenchymal transition through an epigenetic-based mechanism in human lung epithelial cells. PLoS One 2013, 8(5):e64954.

36. Camara J, Jarai G: Epithelial-mesenchymal transition in primary human bronchial epithelial cells is Smad-dependent and enhanced by fibronectin and TNF-alpha. Fibrogenesis Tissue Repair 2010, 3(1):2.

37. Yang K, Song Y, Tang YB, Xu ZP, Zhou W, Hou LN, Zhu L, Yu ZH, Chen HZ, Cui $Y Y$ : mAChRs activation induces epithelial-mesenchymal transition on lung epithelial cells. BMC Pulm Med 2014, 14:53.

38. Byers LA, Diao L, Wang J, Saintigny $P$, Girard L, Peyton $M$, Shen L, Fan $Y$, Giri U, Tumula PK, Nilsson MB, Gudikote J, Tran H, Cardnell RJ, Bearss DJ, Warner SL, Foulks JM, Kanner SB, Gandhi V, Krett N, Rosen ST, Kim ES, Herbst RS, Blumenschein GR, Lee JJ, Lippman SM, Ang KK, Mills GB, Hong WK, Weinstein JN, et al: An epithelial-mesenchymal transition gene signature predicts resistance to EGFR and PI3K inhibitors and identifies Axl as a therapeutic target for overcoming EGFR inhibitor resistance. Clin Cancer Res 2013, 19(1):279-290.

39. Chen YL, Lv J, Ye XL, Sun MY, Xu Q, Liu CH, Min LH, Li HP, Liu P, Ding X: Sorafenib inhibits transforming growth factor beta1-mediated epithelial-mesenchymal transition and apoptosis in mouse hepatocytes. Hepatology 2011, 53(5):1708-1718.

40. Steinestel J, Cronauer MV, Muller J, Al Ghazal A, Skowronek P, Arndt A, Kraft K, Schrader M, Schrader AJ, Steinestel K: Overexpression of p16(INK4a) in urothelial carcinoma in situ is a marker for MAPK-mediated epithelial-mesenchymal transition but is not related to human papillomavirus infection. PLoS One 2013, 8(5):e65189.

41. King TE Jr, Bradford WZ, Castro-Bernardini S, Fagan EA, Glaspole I, Glassberg MK, Gorina E, Hopkins PM, Kardatzke D, Lancaster L, Lederer DJ, Nathan SD, Pereira CA, Sahn SA, Sussman R, Swigris JJ, Noble PW; ASCEND Study Group: A phase 3 trial of pirfenidone in patients with idiopathic pulmonary fibrosis. $N$ Engl J Med 2014, 370(22):2083-2092

42. Richeldi L, du Bois RM, Raghu G, Azuma A, Brown KK, Costabel U, Cottin V, Flaherty KR, Hansell DM, Inoue Y, Kim DS, Kolb M, Nicholson AG, Noble PW, Selman M, Taniguchi H, Brun M, Le Maulf F, Girard M, Stowasser S, Schlenker-Herceg R, Disse B, Collard HR; INPULSIS Trial Investigators: Efficacy and safety of nintedanib in idiopathic pulmonary fibrosis. N Engl J Med 2014, 370(22):2071-2082.

43. Borchers AT, Chang C, Keen CL, Gershwin ME: Idiopathic pulmonary fibrosis-an epidemiological and pathological review. Clin Rev Allergy Immunol 2011, 40(2):117-134.

\section{doi:10.1186/s40169-014-0033-2}

Cite this article as: Sohal et al:: Clinical significance of epithelial mesenchymal transition (EMT) in chronic obstructive pulmonary disease (COPD): potential target for prevention of airway fibrosis and lung cancer. Clinical and Translational Medicine 2014 3:33. 